\title{
Garantía sustancial de edad mínima de responsabilidad penal juvenil
}

Pablo A. De Rosa'

Recibido el 29 de mayo de 2017, aceptado para su publicación el 14 de agosto de 2017

\begin{abstract}
Resumen
En Argentina, la aún vigente Ley $\mathrm{N}^{\circ} 22.278$ (1980), permite la disposición penal de los niños exentos de responsabilidad penal, propia de la doctrina del patronato, contraria al postulado del art. 40 inc. 3.a de la Convención sobre los Derechos del Niños (1989). Pero lo más preocupante es que en los debates legislativos de reforma penal juvenil, se advierte la ausencia de voluntad para establecer una normativa clara sobre qué tipo de intervención estatal corresponde a los niños no punibles, que en la práctica deriva en la justicia penal adolescente. Es por ello que el presente trabajo desarrolla la garantía sustancial de edad mínima de responsabilidad penal, como postulado de construcción del derecho penal juvenil, que limita la intervención del sistema represivo del estado, optando por la prevención del delito por medio de la protección integral de sus derechos.
\end{abstract}

\section{Palabras claves}

Derecho penal juvenil. Edad mínima de responsabilidad penal. Garantía sustancial.

\begin{abstract}
In Argentina, the valid Law $\mathrm{N}^{\circ} 22.278$ (1980), it allows the criminal provision of children exempt from criminal responsibility, own of the doctrine of the patronage, contrary to the postulate of the art. 40 inc. 3.a of the Convention on the Rights of the Child (1989). But is most worrying is that in legislative debates of juvenile criminal reform, there is a lack of will to establish a clear rule on what type of state intervention corresponds to children not punishable, which in practice results in the adolescent criminal justice. It is for this reason that the present paper develops the substantial guarantee of minimum age of criminal responsibility, such as construction of the postulate
\end{abstract}

1. Abogado por la Universidad Católica de Salta (UCASAL), pabloaderosa@hotmail.com 
of juvenile criminal law, which restricts the intervention of the repressive system of the state, opting for the prevention of crime by means of the comprehensive protection of their rights.

\section{Keywords}

Juvenile Criminal Law. Minimum age of criminal responsibility. Substantial guarantee.

\section{Introducción}

El horizonte de proyección del derecho penal adolescente está orientado, en parte, a la explicación de los complejos normativos que habilitan una forma de coacción estatal que es el poder punitivo, caracterizado por la aplicación de sanciones diferentes a otras ramas del saber jurídico: las penas.

En este sentido, las normas jurídicas que habilitan o limitan el ejercicio del poder coactivo del Estado en forma de pena, sería el universo dentro del cual debe construirse un sistema de comprensión que explique cuáles son las hipótesis y condiciones que permiten formular requerimiento punitivo.

Siendo uno de los puntos más discutidos en el derecho penal juvenil, el relacionado con la edad mínima de responsabilidad penal juvenil, resulta necesario realizar una breve consideración respecto de la garantía penal o sustancia de no punibilidad en los niños infractores a la ley penal (art. 40 inc. 3.a CDN).

\section{Garantías penales o sustanciales}

Las garantías se constituyen como límites y prohibiciones impuestos a los poderes públicos de forma cierta, general y abstracta, para tutela de los derechos de libertad de los ciudadanos, frente al poder coercitivo del Estado².

Según los usos lingüísticos corrientes, sustanciales son las normas y las cuestiones del derecho penal relativas a la regulación de los presupuestos de la pena. Por el contrario, son instrumentales las normas de derecho procesal relativas a los métodos y a las formas de comprobación de aquéllos ${ }^{3}$.

El principio de estricta legalidad, con las garantías penales que comporta, tiene la importancia de desplazar el problema sustancial del derecho penal desde el "cuándo castigar" hasta el "cuándo prohibir" incorporando a las formas jurídicas principios ético-políticos y criterios sustanciales de justicia ${ }^{4}$.

2. FERRAJOLI, Luigi, Derechos y garantías. La ley del más débil, 4a edición, Ed. Trotta, Madrid, 2004, p. 16.

3. FERRAJOLI, Luigi, Derecho y Razón. Teoría del garantismo penal, 6a edición, Ed. Trotta, Madrid, 2004, p. 464.

4. Ibídem. 
Al incorporar las garantías penales o sustanciales principios y criterios de justicia, nos da la pauta de su importancia, los cuales no pueden dejar de observarse ante situaciones de alarma social o de extrema gravedad, atento que hacen a la esencia del derecho penal liberal ${ }^{5}$.

Se puede afirmar que el garantismo no prescinde de los valores sustanciales, sino que se configura como una técnica dirigida a satisfacerlos, seleccionándolos, explicitándolos e incorporándolos normativamente en la forma positiva de ley como condiciones de legitimación jurídica de las penas y, con ello, como factores de minimización del poder punitivo legítimo6 .

Así, el sustancialismo penal, resulta un conjunto de reglas y principios que se exigen por las garantías penales como condiciones normativas necesarias para realizar requerimiento punitivo.

\section{Punibilidad. Ubicación como categoría autónoma de la definición de delito}

Comprobada la existencia de un delito, corresponde la habilitación de ejercicio de poder punitivo sobre la persona identificada como sujeto activo. La consecuencia del delito es fundamentalmente la pena estatal.

La punibilidad es entendida entonces como la potestad que el Estado tiene de castigar a una persona por la comisión de un delito.

La expresión punibilidad puede ser utilizada en dos sentidos, como merecimiento de pena o también puede significar la efectiva posibilidad jurídica de aplicar una pena. Esta distinción hace que el delito, por ser una conducta típica, antijurídica y culpable, sea un hecho merecedor de pena, aunque ocasionalmente no sea punible porque no pueda imponerse sanción. De allí que el merecimiento de pena, como posibilidad efectiva de respuesta estatal para el delito, no se siga necesariamente de su aplicación, porque el Estado, en algunos casos, debe inhibirse de ejercer su poder coercitivo por no darse el requisito de punibilidad, entendido como la concreta posibilidad de imposición de la pena merecida ${ }^{7}$.

En este sentido, la característica que hace que una conducta sea punible, depende de otros requisitos además de la existencia del delito, resultando decisiva la utilidad social de la sanción penal.

5. La razón jurídica del estado de derecho, no admite excepción a las reglas, en la jurisdicción el fin nunca justifica los medios, dado que los medios, es decir, las reglas y las formas, son las garantías de verdad y libertad y, como tales, tienen valor para los momentos difíciles más que para los fáciles (conf. FERRAJOLI, Derecho y Razón. Teoría del garantismo penal, ob. cit., p. 830).

6. FERRAJOLI, Derecho y Razón. Teoría del garantismo penal, ob. cit., p.464.

7. ZAFFARONI, Eugenio Raúl, ALAGIA, Alejandro y SLOKAR, Alejandro, Derecho Penal. Parte General, 2a edición, Ed. Ediar, Buenos Aires, 2005, p. 879. 
La doctrina ubica la posibilidad de respuesta punitiva, no como un presupuesto constitutivo de la definición de delito, sino como una consecuencia del mismo, debiendo ser abarcado dentro de la teoría de la responsabilidad ${ }^{8}$.

Situando el concepto de punibilidad fuera de la teoría del delito, puede suceder que al mismo no le siga como consecuencia jurídica la coerción penal, porque la ley determine que ella no debe operar en algún supuesto particular pese a su existencia. Por ello, la operatividad de la respuesta punitiva, no es una cuestión que afecte el delito, sino que se trata de un problema que se plantea y resuelve en la teoría de la responsabilidad penal, que usualmente se conocen como excusas absolutorias, que no son más que causas que impiden en concreto aquella posibilidad de respuesta punitiva?.

\section{Eximentes de punibilidad o excusas absolutorias}

Partiendo del principio de que la pena debe ser estricta y evidentemente necesaria, como así también la mínima de las posibles ${ }^{10}$, por razones de conveniencia política o político criminales ajenas a la gravedad de la infracción, el legislador renuncia en algunos supuestos a la aplicación de una pena no existiendo responsabilidad, pese a existir culpabilidad.

Para que resulte legítima la imposición de una pena, no basta la existencia del delito, sino que es preciso que el autor aparezca como un sujeto idóneo para responder penalmente.

Siendo la punibilidad objeto de estudio en la teoría de la responsabilidad, las eximentes de punibilidad que impiden castigar a una determinada persona, no afectan la objetiva relevancia penal del hecho subsistiendo su antijuricidad típica imputable al sujeto, sino que excepcionalmente se impide el castigo cuando el mismo es cometido por una persona determinada ${ }^{11}$.

Las causas que excluyen la posibilidad de respuesta punitiva penales ${ }^{12}$ tienen lugar cuando existen causas que excluyen la penalidad, o causas que la cancelan, teniendo la particularidad de ser siempre de carácter personal. Cuando las mismas son anteriores o concomitantes al hecho excluyen la penalidad; y cuando advienen con posterioridad al hecho, cancelan la punibilidad.

8. ZAFFARONI, ob. cit., pp. 390-391; MIR PUIG, Santiago, Derecho Penal. Parte General, Ed. B de F, Buenos Aires, 2004, p. 152.; FONTÁN BALESTRA, Carlos, Tratado de Derecho Penal, T. III, Parte General, 7a edición, Ed. Abeledo Perrot, Buenos Aires, 1990, p. 446.

9. ZAFFARONI, ob. cit., p. 879.

10. FERRAJOLI, Derecho y Razón. Teoría del garantismo penal, ob. cit., p.394.

11. MIR PUIG, ob. cit., p. 152.

12. A diferencia de las procesales cuya operatividad de la coerción penal se relacionan con presupuestos constitucionales del propio debido proceso penal, como son los requisitos de perseguibilidad referente a ciertos delitos o a la acción procesal en general (conf. ZAFFARONI, ob. cit., p. 879) 
Las causas excluyentes de punibilidad descartan desde el comienzo la operatividad de la coerción penal a partir del mismo momento del hecho y, siendo de carácter personal, la misma no ampara a los partícipes ni a los coautores ${ }^{13}$.

En síntesis, la culpabilidad por sí sola que es captada por el derecho penal, no justifica la pena, siempre tiene que existir además la necesidad práctica de hacer uso de ella. Las causas eximentes de punibilidad o excusas absolutorias son entendidas como verdaderos delitos sin pena, tratándose de situaciones en que la ley, por motivos de utilidad y política criminal, considera preferible prescindir de la pena por razones especialísimas ${ }^{14}$.

\section{Garantía penal o sustancial de no punibilidad en los niños. Edad mínima de responsabilidad penal juvenil}

Sobre la base de lo expuesto, la no punibilidad del menor que no haya alcanzado la edad mínima de responsabilidad penal juvenil conforme la legislación nacional ${ }^{15}$, configura una causa personal de exclusión de punibilidad, entendiendo tal circunstancia como la absoluta imposibilidad del Estado de aplicar una sanción penal.

Desde el marco político criminal, existen ciertos sectores en los que la no imposición de sanciones no altera el mantenimiento del orden social. La pena no sólo es innecesaria desde el plano de los objetivos político criminales, sino intolerable y abusivo; por lo tanto, para estos sujetos no cabe hablar de necesidad de pena ${ }^{16}$.

La garantía penal o sustancial de establecer una edad por debajo de la cual el Estado está obligado renunciar a toda intervención estatal coactiva, se encuentra receptada en el art. 40.3.a de la $\mathrm{CDN}^{17}$.

13. ZAFFARONI, ob. cit., p. 880 .

14. FONTÁN BALESTRA, ob. cit., p. 446.

15. En el supuesto de la legislación de la República Argentina, el Art. 1 de la ley $N^{\circ} 22.278$ que establece que: "No es punible el menor que no haya cumplido dieciséis años de edad. Tampoco lo es el que no haya cumplido dieciocho años, respecto de delitos de acción privada o reprimidos con pena privativa de la libertad que no exceda de dos años, con multa o con inhabilitación (Ley $\mathrm{N}^{\circ} 22.278$-texto según ley $\mathrm{N}^{\circ}$ 22.803- Régimen Penal de Menores, promulgada el 25/8/1980 y publicada el 28/8/1980). En el caso de la normativa de la República de El Salvador, el Art. 2 de la Ley Penal Juvenil, establece que esa ley se aplicará a las personas mayores de doce años de edad y menores de dieciocho; con respeto a los menores que no hubiesen cumplido doce años de edad y presenten una conducta antisocial, los mismos no estarán sujetos al régimen jurídico especial, ni al común; están exentos de responsabilidad y, en su caso, deberá darse aviso inmediatamente al Instituto Salvadoreño de Protección al Menor para su protección integral (Ley Penal Juvenil, Decreto Legislativo $\mathrm{N}^{\circ} 863,27 / 4 / 1994$, publicado el 8/6/1994).

16. CANTARERO, Rocío, Delincuencia juvenil y sociedad en transformación: derecho penal y procesal de menores, Ed. Montecorvo S.A., Madrid, 1988, p. 113.

17. En igual sentido art. 4.1 Reglas de Beijing (1985), art. 11.a Reglas de La Habana (1990), y art. 14.c Directrices de Viena (1997). 
Esta edad mínima de punibilidad garantiza que por debajo de ella no se habilitaría castigo a los niños y adolescentes que realizaran conductas prohibidas por la ley penal y, consecuentemente, el ámbito de libertad se encuentra exento de intervención punitiva ${ }^{18}$.

La misma, debe ser fijada teniendo en cuenta una política criminal de Estado, en razón de que los jóvenes infractores se encuentran en una etapa temprana de la vida e implica un obstáculo a la intervención coactiva.

Esta renuncia puede tener que ver con cuestiones de justicia, porque resulta inhumano aplicar un castigo a un joven de muy corta edad o porque la comunidad no considera que deba reprocharse penalmente los hechos cometidos por estos jóvenes, asumiendo cierta responsabilidad social o la inconveniencia de disponer recursos económicos para incrementar el sistema penal en desmedro de políticas sociales que pueden ser útiles para superar estos conflictos ${ }^{19}$.

Este concepto de formas de corresponsabilización en relación a los niños infractores a la ley penal, hacen que se acepte el hecho delictivo como expresión de, al menos, dos transgresiones sustancialmente unidas: la del joven que actúa por fuera de la norma jurídica, pero también la del Estado que no actúa eficazmente a través de políticas sociales ${ }^{20}$. Si no se piensa la problemática desde esta perspectiva, la responsabilidad es depositada sólo en el niño infractor a la ley penal, sin acusar con igual firmeza la realidad de las instituciones en cuyo marco se pretende que cambie de conducta, ni la ausencia de esfuerzos por modificar el entorno social del que surgió la conducta transgresora ${ }^{21}$.

Es así, que aplicar una sanción a un menor no punible o exento de responsabilidad penal, implicaría una grave perturbación de su formación y desarrollo, con lo cual, desde la perspectiva de las consecuencias externas, no es aconsejable la utilización del derecho penal, por lo que sólo le cabe al Estado asumir su función de asistencia social general ${ }^{22}$.

Este perdón judicial resulta abarcativo de un juicio de culpabilidad y expresa la abdicación de castigo del joven infractor, siendo una medida que claramente ejemplifica el tipo de lógica que inspira la justicia penal juvenil.

18. ZURZOLO SUÁREZ, Santiago, “Niños, niñas y adolescentes: inimputables o no punibles?", en http://www.infojus.gov.ar, 23/5/2012 (Id Infojus: DACF120097), punto IV.

19. FREEDMAN, Diego y TERRAGNI, Martiniano, "La respuesta de la Corte Suprema frente a los imputados menores de edad no punibles", Suplemento La Ley, Penal y Procesal Penal, 23/12/2008, p. 29.

20. MARCÓN, Osvaldo, La responsabilización penal juvenil como nuevo relato cultural. ¿Del "amor por los niños" al "odio hacia los menores"?, 1a edición, Espacio Editorial, Buenos Aires, 2013, p.49. 21. MARCÓN, ob. cit., p. 45.

22. BUSTOS RAMíREZ, Juan, "Imputabilidad y edad penal", en cuadernos de posgrado, México, Unam/Acatlán, Serie A, N² 2, 1988, p. 89. 
A los niños no punibles se les garantiza por medio de la CDN que no pueden recibir respuestas provenientes del aparato punitivo estatal, a través de jueces penales que utilizan herramientas claramente coercitivas. Cualquier actividad desplegada desde la jurisdicción penal que posea injerencia sobre los derechos y garantías de los menores no punibles, carece de legitimación por no existir los presupuestos previos y necesarios para que el Estado pueda desplegar sus facultades dentro de un proceso penal, más allá de la comprobación del delito y la participación del niño en el mismo, respetando principios constitucionales.

Demostrada la existencia del hecho delictivo y participación en el mismo del niño exento de responsabilidad penal, y a su vez ciertos tipos de carencias identificadas a nivel de lo social, opera la garantía sustancial de no punibilidad, cambia el tipo de intervención, debido a que tal conducta no puede tener consecuencias penales en el sujeto. Se produce una derivación automática al sistema de protección ${ }^{23}$.

No puede perderse de vista que el objeto y fin de la CDN es la protección integral del niño, operando el límite etario con naturaleza de una medida de protección de la condición de niño, implicando la exclusión de la punibilidad frente a la comisión de un hecho prohibido penalmente. Esta garantía de no punibilidad, es una institución definitivamente protectiva y de cuidado de la niñez, garantizadora de espacios de libertad, destinada a proteger una etapa de la vida en desarrollo ${ }^{24}$.

Pero esta derivación al sistema de protección de derechos aludida, no implica en modo alguno un mensaje de irresponsabilidad o impunidad. En el marco de la estrategia integral que se elabore, será esencial una intervención con la finalidad de incorporar en la esfera psíquica, la comprensión del significado que su accionar tiene para la comunidad en la que vive ${ }^{25}$. Esta labor orientada a fortalecer la estructuración subjetiva del niño, debe estar dirigida a la inscripción de las normas que regulan la convivencia social, otorgándole la oportunidad de reflexionar sobre las consecuencias de su conducta penal ${ }^{26}$.

Dicho en otros términos, la respuesta del sujeto no será apreciada desde el derecho penal, sino que será considerada desde otras ramas del derecho. En ningún caso se niega la capacidad de respuesta del sujeto, lo cual sería negarle su carácter de persona cuando se plantea un juicio de inimputabilidad, sino que su responsabilidad no puede moverse en el ámbito penal ${ }^{27}$.

23. BELOFF, Mary, “Algunas confusiones en torno a las consecuencias jurídicas de la conducta transgresora de la ley penal en los nuevos sistemas de justicia juvenil latinoamericanos”, publicado en Justicia y Derechos del Niño, N³, UNICEF, Buenos Aires, 2001, p. 24.

24. ZURZOLO SUÁREZ, ob. cit., punto IV.

25. BELOFF, Mary, “Argumentos para una discusión pendiente acerca del futuro de la justicia juvenil en la República Argentina”, en AA.VV., Estudios sobre edad penal y derechos del niño, dirección Mary Beloff, Ed. Ad-Hoc, Buenos Aires, 1a edición, 2013, p. 46.

26. GIACOIA, Marcelo y CICCOLI, Sebastián, "Los imputados no punibles en la provincia de Buenos Aires y las medidas de seguridad”, en AA.VV., Estudios sobre edad penal y derechos del niño, dirección Mary Beloff, Ed. Ad-Hoc, Buenos Aires, 1a edición, 2013, p. 149.

27. BUSTOS RAMÍREZ, ob. cit., p. 84. 
Por ello, esta desviación del niño no punible hacia un sistema de protección da prioridad a la utilización de otras herramientas jurídicas alternativas para el abordaje de los conflictos humanos, consolidando el principio de ultima ratio del derecho penal, respetando la necesidad de establecer por ley una edad límite por debajo de la cual no se lo puede declarar responsable penalmente y no se permita privar de libertad a un niño ${ }^{28}$.

Esta afirmación se encuentra contemplada por el Comité en la Observación General $N^{\circ} 10$ al indicar que el art. 40.3.a de la CDN crea la obligación para los Estados Parte de establecer una edad mínima a efectos de responsabilidad penal (EMRP). Esa edad mínima significa lo siguiente: los niños que cometen un delito cuando todavía no han cumplido esa edad mínima no podrán considerarse responsables en un procedimiento penal; si es necesario, podrán adoptarse medidas especiales de protección en el interés superior de esos niños ${ }^{29}$.

Estas “medidas especiales de protección en el interés superior de esos niños”, no son otras que las contempladas en las leyes previstas para situaciones de vulneración de derechos y su consecuente promoción y protección integral de los mismos.

Tales razones determinan que respecto de aquellos niños que no hubieren cumplido la edad para ser declarados penalmente responsables, esto es que el Estado renuncia a su potestad punitiva, deberá prohibirse la posibilidad de intervenir mediante medidas coactivas. Solo si hay amenaza o violación de los derechos de los niños, la autoridad administrativa podrá aplicar medidas de protección y restitución de derechos, que en ningún caso podrán ser privaciones de libertad $^{30}$.

\section{Conclusión}

Quienes aún no asimilan los cambios postulados por la CDN padecen de una confusión, que en la práctica permite el encierro o privación de libertad de jóvenes faltos de asistencia, que nacieron bajo la vigencia de principios sociales, culturales y morales particulares de sus ámbitos de convivencia.

Si estas circunstancias hacen que deriven en infracción a la ley penal siendo niños no punibles, la realidad cotidiana del sistema judicial penal juvenil Argentino hace que los mismos puedan ser pasibles de injerencia penal más allá de los límites de su intervención convencional.

28. Art. 11.a Reglas de La Habana (1990).

29. Comité de los Derechos del Niño de la ONU, Observación General N ${ }^{\circ} 10$. Los derechos del niño en la justicia de menores, CRC/C/GC/10, Ginebra, 25/4/2007, párrafo 31.

30. UNICEF - Secretaria de Derechos Humanos de la Nación, Estándares mínimos de derechos humanos para una nueva ley de justicia penal juvenil, Buenos Aires, 2005, p. 7. 
Es la garantía penal o sustancial de no punibilidad en los niños, la que mediante el establecimiento de una edad mínima de responsabilidad penal, implica la absoluta imposibilidad del Estado de emplear una sanción penal.

El art. 40.3.a de la CDN debe ser concebido como un verdadero límite y prohibición a los poderes públicos de intervención coercitiva respecto de los niños no punibles, poniéndose en riesgo la responsabilidad internacional del Estado ante cualquier injerencia penal.

Esta garantía de eximición personal de punibilidad, deslegitima el abordaje penal del niño infractor y deriva a la autoridad administrativa la posibilidad de aplicar medidas de protección y restitución de derechos en el marco de su interés superior.

\section{Bibliografía}

1. BELOFF, Mary, "Algunas confusiones en torno a las consecuencias jurídicas de la conducta transgresora de la ley penal en los nuevos sistemas de justicia juvenil latinoamericanos", publicado en Justicia y Derechos del Niño, N 3, UNICEF, Buenos Aires, 2001.

2. BELOFF, Mary, “Argumentos para una discusión pendiente acerca del futuro de la justicia juvenil en la República Argentina”, en AA.VV., Estudios sobre edad penal y derechos del niño, dirección Mary Beloff, Ed. Ad-Hoc, Buenos Aires, 1a edición, 2013.

3. BUSTOS RAMÍREZ, Juan, "Imputabilidad y edad penal", en Cuadernos de posgrado, México, Unam/Acatlán, Serie A, N², 1988.

4. CANTARERO, Rocío, Delincuencia juvenil y sociedad en transformación: derecho penal y procesal de menores, Ed. Montecorvo S.A., Madrid, 1988.

5. Comité de los Derechos del Niño de la ONU, Observación General № 10, Los derechos del niño en la justicia de menores, $\mathrm{CRC} / \mathrm{C} / \mathrm{GC} / 10$, Ginebra, 25/4/2007.

6. Directrices de Acción sobre el Niño en el Sistema de Justicia Penal (Directrices de Viena), Resolución 1997/30 del Consejo Económico y Social de las Naciones Unidas, 21/7/1997.

7. FERRAJOLI, Luigi, Derechos y garantías. La ley del más débil, 4a edición, Ed. Trotta, Madrid, 2004.

8. FERRAJOLI, Luigi, Derecho y Razón. Teoría del garantismo penal, 6a edición, Ed. Trotta, Madrid, 2004.

9. FONTÁN BALESTRA, Carlos, Tratado de Derecho Penal, T. III, Parte General, 7a edición, Ed. Abeledo Perrot, Buenos Aires, 1990.

10. FREEDMAN, Diego y TERRAGNI, Martiniano, "La respuesta de la Corte Suprema frente a los imputados menores de edad no punibles", Suplemento La Ley, Penal y Procesal Penal, 23/12/2008.

11. GIACOIA, Marcelo y CICCOLI, Sebastián, "Los imputados no punibles en la provincia de Buenos Aires y las medidas de seguridad”, en AA.VV., Estudios 
sobre edad penal y derechos del niño, dirección Mary Beloff, Ed. Ad-Hoc, Buenos Aires, 1a edición, 2013.

12. Ley $N^{\circ} 22.278$ de la Nación (texto según ley $N^{\circ} 22.803$ ), Régimen penal de menores, sanción y promulgación el 25/8/1980, publicada el 28/8/1980.

13. Ley Penal Juvenil, Decreto Legislativo $N^{\circ} 863,27 / 4 / 1994$, publicado el 8/6/1994, República de El Salvador.

14. MARCÓN, Osvaldo, La responsabilización penal juvenil como nuevo relato cultural. ¿Del “amor por los niños” al “odio hacia los menores”?, 1a edición, Espacio Editorial, Buenos Aires, 2013.

15. MIR PUIG, Santiago, Derecho Penal. Parte General, Ed. B de F, Buenos Aires, 2004.

16. Reglas de las Naciones Unidas para la Protección de los Menores Privados de Libertad (Reglas de La Habana), adoptadas por la Asamblea General de las Naciones Unidas, Resolución 45/113, 14/12/1990.

17. Reglas Mínimas de las Naciones Unidas para la Administración de la Justicia de Menores (Reglas de Beijing), adoptadas por la Asamblea General de las Naciones Unidas, Resolución 40/33, 28/11/1985.

18. UNICEF - Secretaria de Derechos Humanos de la Nación, Estándares mínimos de derechos humanos para una nueva ley de justicia penal juvenil, Buenos Aires, 2005.

19. ZAFFARONI, Eugenio Raúl, ALAGIA, Alejandro y SLOKAR, Alejandro, Derecho Penal. Parte General, 2a edición, Ed. Ediar, Buenos Aires, 2005.

20. ZURZOLO SUÁREZ, Santiago, "Niños, niñas y adolescentes: inimputables o no punibles?”, en http://www.infojus.gov.ar, 23/5/2012 (Id Infojus: DACF120097). 